\title{
A PROSPECTIVE STUDY TO EVALUATE CORRELATION BETWEEN REID'S COLPOSCOPIC INDEX IMPRESSION AND BIOPSY HISTOLOGY
}

\author{
Sonal Kulshreshtha1, Richa Chouksey², Pratibha Garg ${ }^{3}$ \\ ${ }^{1}$ Associate Professor, Department of Obstetrics and Gynaecology, Gajra Raja Medical College, Gwalior. \\ ${ }^{2}$ Senior Resident, Department of Obstetrics and Gynaecology, Gajra Raja Medical College, Gwalior. \\ ${ }^{3}$ Assistant Professor, Department of Obstetrics and Gynaecology, Gajra Raja Medical College, Gwalior.
}

\section{ABSTRACT}

\section{BACKGROUND}

Aims and Objectives- 1 . To correlate the findings in women with unhealthy cervix by cytology, colposcopy and colposcopic directed biopsies; 2 . To assess the utility of colposcopy in detecting the premalignant and malignant lesions of the cervix.

\section{MATERIALS AND METHODS}

It was a prospective study which included 100 patients admitted at Kamla Raja Hospital, Gwalior. Pap smear, colposcopy and colposcopic-guided biopsy was done and results correlated. Colposcopic diagnosis was based on Reid Colposcopic Index.

\section{RESULTS}

The mean age of the women in the study was 37.85 years. The commonest symptom was recurrent white discharge per vagina (79\%). Majority of the study groups were para 2 (33\%) and para 3 (34\%). Pap smear revealed squamous intraepithelial lesions in 19\% cases, whereas $77 \%$ has inflammatory smears and in $4 \%$ cases smears were within normal limits. The sensitivity and specificity of Pap smear was $43.2 \%$ and $95.2 \%$ respectively. Positive Pap smear [LSIL/HSIL] was significantly associated with LSIL/HSIL/malignancy [p < 0.001, Chi $\left.^{2}(22.4)\right]$. RCI (6.8) was significantly associated with malignancy $\left(\mathrm{p}=0.001, \mathrm{Chi}^{2}=10.5\right) . \mathrm{High}^{2}$ RCI (6 - 8) was significantly associated with HSIL $\left(\mathrm{p}<0.001, \mathrm{Chi}^{2}=31.4\right)$.

\section{CONCLUSION}

Colposcopy is useful in detecting premalignant and malignant lesions of the cervix. Colposcopy and cytology used together in patients of cervical lesions have relatively higher chances of detecting squamous intraepithelial lesions.

\section{KEYWORDS}

Cervical Biopsy, Cervical Cancer, Pap Smear, Reid's Colposcopic Index.

HOW TO CITE THIS ARTICLE: Kulshreshtha S, Chouksey R, Garg P. A prospective study to evaluate correlation between Reid's colposcopic index impression and biopsy histology. J. Evolution Med. Dent. Sci. 2017;6(30):2455-2461, DOI: $10.14260 /$ Jemds/2017/530

\section{BACKGROUND}

\section{Prevention Is Better Than Cure}

Cheating cancer is all about preventing cancer, if that unfortunately is not possible then detecting it early enough to give our bodies a chance to fight.

Unhealthy cervix is a very common finding in our country due to poor genital hygiene, malnutrition and multiparity. ${ }^{1}$ Cancer of uterine cervix is a serious health problem in India. Every year in India 122,844 women are diagnosed with cervical cancer and 67,477 die from the disease. India has a population of 432.2 million women aged 15 years and older who are at risk of developing cancer. It is the second most common cancer in women aged 15 - 44 years. ${ }^{2}$ Fortunately, the incidence of cervical cancer has decreased by more than $50 \%$ in the past 30 years, largely due to the increasing use of cervical cancer screening with cervical cytology. ${ }^{3}$

Financial or Other, Competing Interest: None.

Submission 07-03-2017, Peer Review 31-03-2017,

Acceptance 06-04-2017, Published 13-04-2017.

Corresponding Author:

Dr. Sonal Kulshreshtha,

\#403, Satyam Residency,

Satyadev Nagar,

Gandhi Road,

Gwalior-474011.

E-mail: drsonalkulshreshtha@gmail.com

DOI: $10.14260 /$ jemds $/ 2017 / 530$
Screening aims to detect the disease at the precancer stage, when it is amenable to simple treatment and cure. This reduction in mortality through screening is due to-

1) An increase in the detection of invasive cancer at early stages, when the 5-year survival rate is approximately $92 \% .4$

2) The detection and treatment of pre-invasive lesions, which reduces the overall incidence of invasive cancer.

In fact, the incidence of cervical cancer in the United States has decreased from 14.8 cases per 100,000 women in 1975 to only 6.5 cases per 100,000 women in $2006.5,6$

Although worldwide cervical cancer rates have decreased dramatically with the increase in screening efforts, incidence and prevalence in developing countries remains high due to ignorance and unawareness about screening programs among women.

India accounts for one-sixth of the world's population, also bears one-fifth of the world's burden of cervical cancer.

Invasive cancer of cervix has been considered a preventable cancer, because it has a long pre-invasive state, cervical cytology screening programs are available and the treatment of pre-invasive lesions is effective. ${ }^{7}$ The unique accessibility of the cervix to direct visualisation and the possibility of cellular and tissue sampling has permitted extensive investigations on lesions of cervix. There is 
excellent evidence that invasive cancer of the cervix develops from carcinoma in situ or dysplasia. Therefore, screening of the cervix by cytology and colposcopy can significantly reduce the rate of invasive cancers.

Downstaging for cervical cancer is detection of the disease at an earlier, curable stage in asymptomatic women using a simple speculum for visual examination of the cervix. Detection is done by nurses and other paramedical health workers using a simple speculum for visual inspection of cervix in places where prevalence of cancer is high and cytological screening is not available. ${ }^{8}$

Pap smear has become a routine method of cervical cancer screening. Its clinical utilisation is rapidly expanding due to the simplicity of the technique, cost-effectiveness and less time taken to obtain the diagnosis. ${ }^{9}$ Cytology has got certain limitations like low sensitivity of $51 \%$ and a false negative rate of $49 \%$.

The colposcope is a low power, binocular microscope for study of surface epithelium and underlying connective tissue stroma along with vascular pattern. ${ }^{10}$ It is an optical method of visualising lower female genital tract under bright illumination using stereoscopic vision. Colposcopy is complementary as well as superior to cytology. It is a simple non-invasive OPD procedure. It helps in determining indications for cervical biopsy, locating sites and the extent of biopsy. It helps in avoiding traumatic diagnostic methods like cervical conization for minor lesions and at the same time significant lesions are not overlooked.

Colposcopic directed biopsy of suspicious areas provides the final diagnosis in most situations and is taken as the gold standard in diagnosis of neoplastic lesions.
The present prospective study was carried out at Kamla Raja Hospital, G.R. Medical College and J.A. Group of Hospitals, Gwalior (M.P.) for a period of 1 year from 2014 - 2015. One hundred cases who fulfilled the selection criteria were recruited for the study.

\section{Inclusion Criteria}

1. Recurrent episodes of white discharge per vagina.

2. Intermenstrual bleeding, post-coital bleeding or postmenopausal bleeding.

3. Suspicious looking cervix (leukoplakia, cervical ectopy, etc.).

\section{Exclusion Criteria}

1. Pregnant women.

2. Clinically visible growth on cervix.

3. Prior hysterectomy or procedure on the cervix.

4. Unmarried.

Written and informed consent were obtained from all the participants after brief explanation of the procedure. Menstrual and obstetric history was taken in relation to the presenting complaints. History of any previous surgery on cervix was noted. Examination was done in dorsal position using Cusco's self-retaining speculum.

A Pap smear was taken using Ayre's spatula. Revised Bethesda System was used for describing Pap smear results. In all women, colposcopy was done irrespective of Pap smear results.

Findings were recorded and colposcopy diagnosis was made based on Modified Reid Colposcopic Index (RCI).

\section{MATERIALS AND METHODS}

The Modified Reid Colposcopic Index (RCI)*

\begin{tabular}{|c|c|c|c|}
\hline Colposcopic Signs & Zero Point & One Point & Two Points \\
\hline Colour & $\begin{array}{l}\text { Low-intensity acetowhitening (not } \\
\text { completely opaque); indistinct } \\
\text { acetowhitening; transparent or } \\
\text { translucent acetowhitening. } \\
\text { Acetowhitening beyond the margin of the } \\
\text { transformation zone, pure snow-white } \\
\text { colour with intense surface shine (rare) }\end{array}$ & $\begin{array}{l}\text { Intermediate shade- } \\
\text { grey/white colour and shiny } \\
\text { surface (most lesions should } \\
\text { be scored in this category) }\end{array}$ & Dull, opaque, oyster white, grey \\
\hline $\begin{array}{l}\text { Lesion margin and } \\
\text { surface configuration }\end{array}$ & $\begin{array}{l}\text { Microcondylomatous or micropapillary } \\
\text { contour } \\
\text { Flat lesions with indistinct margins } \\
\text { Feathered or finely scalloped margins } \\
\text { Angular, jagged lesions } \\
\text { Satellite lesions beyond the margin of the } \\
\text { transformation zone }\end{array}$ & $\begin{array}{c}\text { Regular-shaped, symmetrical } \\
\text { lesions with smooth, straight } \\
\text { outlines }\end{array}$ & $\begin{array}{c}\text { Rolled, peeling edges } \\
\text { Internal demarcations between } \\
\text { areas of differing colposcopic } \\
\text { appearance- a central area of } \\
\text { high-grade change and } \\
\text { peripheral area of low-grade } \\
\text { change }\end{array}$ \\
\hline Vessels & $\begin{array}{c}\text { Fine/uniform-calibre vessels- closely and } \\
\text { uniformly placed } \\
\text { Poorly formed patterns of fine punctation } \\
\text { and/or mosaic } \\
\text { Vessels beyond the margin of the } \\
\text { transformation zone } \\
\text { Fine vessels within microcondylomatous } \\
\text { or micropapillary lesions }\end{array}$ & Absent vessels & $\begin{array}{l}\text { Well-defined coarse punctation } \\
\text { or mosaic, sharply demarcated- } \\
\text { and randomly and widely placed }\end{array}$ \\
\hline Iodine staining & $\begin{array}{l}\text { Positive iodine uptake giving mahogany } \\
\text { brown colour } \\
\text { Negative uptake of insignificant lesion, i.e. }\end{array}$ & $\begin{array}{l}\text { Partial iodine uptake- } \\
\text { variegated, speckled } \\
\text { appearance }\end{array}$ & $\begin{array}{l}\text { Negative iodine uptake of } \\
\text { significant lesion, i.e. yellow } \\
\text { staining by a lesion already }\end{array}$ \\
\hline
\end{tabular}




\begin{tabular}{|c|c|c|c|}
\hline Colposcopic Signs & Zero Point & One Point & Two Points \\
\hline & $\begin{array}{c}\text { yellow staining by a lesion scoring } \\
\text { three points or less on the first three } \\
\text { criteria }\end{array}$ & $\begin{array}{c}\text { scoring four points or more on } \\
\text { the first three criteria } \\
\text { Areas beyond the margin of the } \\
\text { transformation zone, conspicuous on } \\
\text { colposcopy, evident as iodine-negative } \\
\text { areas (such areas are frequently due to } \\
\text { parakeratosis) }\end{array}$ & \\
\hline
\end{tabular}

Scores of 0 - 2: Predictive of minor lesion (CIN1 or HPV)

3 - 4: Middle grade lesion (CIN 1 - II)

5 - 8: Significant lesion (CIN II - III)

Biopsy was taken from abnormal area under colposcopy guidance using cervical punch biopsy forceps. The specimen was sent for histopathological examination in formalin solution. Slides were analysed by senior consultant pathologist.

\section{Biopsy results were Categorised as-}

1. Cervicitis/metaplasia.

2. CIN-1 (mild dysplasia/correlating with LSIL).

3. CIN- $2 / 3$ (moderate-to-severe dysplasia/correlating with HSIL).

4. Squamous cell carcinoma.

\section{RESULTS}

\begin{tabular}{|c|c|c|}
\hline Age Group & Number of Cases (n = 100) & Percentage \\
\hline $20-30$ yrs. & 16 & 16 \\
\hline $31-40$ yrs. & 41 & 41 \\
\hline $41-50$ yrs. & 32 & 32 \\
\hline$>50$ yrs. & 11 & 11 \\
\hline \multicolumn{2}{|c|}{ Table 1. Distribution of Cases according to Age } \\
\hline
\end{tabular}

Maximum number of cases were found to be in the age group 31 - 40 years (41\%). The mean age was 37.85 years.

\begin{tabular}{|c|c|c|}
\hline Parity & Number of Cases $(n=100)$ & Percentage \\
\hline Nullipara & 5 & 5 \\
\hline Para one & 5 & 5 \\
\hline Para two & 33 & 33 \\
\hline Para three & 34 & 34 \\
\hline$\geq$ Para four & 23 & 23 \\
\hline \multicolumn{3}{|c|}{ Table 2. Distribution of Cases based on Parity } \\
\hline
\end{tabular}
(34\%).

Majority of the study group were para 2 (33\%) and para 3

\begin{tabular}{|c|c|c|}
\hline Symptoms & $\begin{array}{c}\text { Number of Cases } \\
(n=100)\end{array}$ & Percentage \\
\hline Recurrent white discharge & 69 & 69 \\
\hline Post coital bleeding & 10 & 10 \\
\hline Intermenstrual bleeding & 4 & 4 \\
\hline Postmenopausal bleeding & 8 & 8 \\
\hline Menorrhagia & 9 & 9 \\
\hline
\end{tabular}

The commonest symptom was recurrent white discharge per vagina $(69 \%)$.

\begin{tabular}{|c|c|c|}
\hline Age at First Intercourse & Number of Cases & Percentage \\
\hline Less than 20 years & 93 & 93 \\
\hline More than 20 years & 7 & 7 \\
\hline \multicolumn{2}{|c|}{ Table 4. Distribution of Cases } \\
based on Age at First Intercourse \\
\hline
\end{tabular}

In $93 \%$ cases, the age of intercourse is $<20$ years.

\begin{tabular}{|c|c|c|}
\hline Outcome & Number of Cases (n = 100) & Percentage \\
\hline Normal & 4 & 4 \\
\hline Inflammatory & 77 & 77 \\
\hline LSIL & 9 & 9 \\
\hline HSIL & 10 & 10 \\
\hline Malignancy & 0 & 0 \\
\hline \multicolumn{3}{|c|}{ Table 5. Pap Smear Results } \\
\hline
\end{tabular}

Pap smear revealed that $77 \%$ had an inflammatory smear and $19 \%$ had a positive Pap smear. The result of Pap smear was considered positive if it revealed LSIL, HSIL, carcinoma in situ or invasive cancer. Among 19 positive cases there were 9 LSIL, 10 HSIL and no case of malignancy

\begin{tabular}{|c|c|c|}
\hline $\begin{array}{c}\text { Modified Reid's } \\
\text { Colposcopic Index }\end{array}$ & Number of Cases & Percentage \\
\hline $0-2$ & 29 & 29 \\
\hline $3-4$ & 48 & 48 \\
\hline $5-8$ & 23 & 23 \\
\hline \multicolumn{2}{|c|}{ Table 6. Colposcopy Results } \\
\hline
\end{tabular}

On Colposcopy 29\% women were found to have an RCI 0 2 (likely to be CIN 1), 48\% 3 - 4 (overlapping lesion: likely to be CIN 1 or CIN 2) and 23\% 5 - 8 (likely to be CIN 2 - 3).

\section{RCI (Overall Score) Histology}

$0-2$

$3-4$

Likely to be CIN 1

$5-8$

Overlapping lesion: likely to be CIN 1 or CIN 2

Likely to be CIN 2-3

\begin{tabular}{|c|c|c|}
\hline Outcome & $\begin{array}{c}\text { Number of } \\
\text { Cases }(n=100)\end{array}$ & Percentage \\
\hline Normal & 03 & 03 \\
\hline Cervicitis/metaplasia & 60 & 60 \\
\hline Mild dysplasia/LSIL/CIN1 & 19 & 19 \\
\hline $\begin{array}{c}\text { Moderate to severe dysplasia/ } \\
\text { HSIL/ CIN2/CIN3 }\end{array}$ & 15 & 15 \\
\hline Malignancy & 03 & 03 \\
\hline
\end{tabular}


The positive biopsy includes 37 cases out of 100. Biopsy was considered positive, if it revealed LSIL and above. It includes 19 mild dysplasias (LSIL), 15 moderate-to-severe dysplasias (HSIL) and 03 malignancies. Out of 03 malignancies, none had visible growth on per speculum examination.

\begin{tabular}{|c|c|c|c|c|c|c|}
\hline \multirow{2}{*}{ Pap Smear } & \multicolumn{5}{|c|}{ Biopsy } & \multirow{2}{*}{ Total } \\
\cline { 2 - 6 } & Normal & Cervicitis & LSIL & HSIL & Malignancy & $4(4 \%)$ \\
\hline Normal & $0(0 \%)$ & $4(4 \%)$ & $0(0 \%)$ & $0(0 \%)$ & $0(0 \%)$ & $77(77 \%)$ \\
\hline Inflammatory & $3(3 \%)$ & $53(53 \%)$ & $15(15 \%)$ & $6(6 \%)$ & $0(0 \%)$ & $9(9 \%)$ \\
\hline LSIL & $0(0 \%)$ & $3(3 \%)$ & $2(2 \%)$ & $3(3 \%)$ & $1(1 \%)$ & $10(10 \%)$ \\
\hline HSIL & $0(0 \%)$ & $0(0 \%)$ & $2(2 \%)$ & $6(6 \%)$ & $2(2 \%)$ & $100(100 \%)$ \\
\hline Total & $3(3 \%)$ & $60(60 \%)$ & $19(19 \%)$ & $15(15 \%)$ & $3(3 \%)$ & \\
\hline
\end{tabular}

19 cases out of 100 women were positive on Pap smear; 37 out of 100 women were positive on Biopsy. Pap smear was positive in 16 out of 37 biopsy proven positive cases; 15 cases of LSIL and 6 cases of HSIL were under-reported as inflammatory on Pap smear and 3 cases of cervicitis/metaplasia were over-reported, as LSIL on Pap smear.

Positive Pap smear includes LSIL and HSIL.

\begin{tabular}{|c|c|c|c|}
\hline \multirow{2}{*}{ Pap Smear } & \multicolumn{2}{|c|}{ Biopsy } & \multirow{2}{*}{ Total } \\
\cline { 2 - 3 } & LSIL/HSIL/ Malignancy & Normal/ Cervicitis & $19(19 \%)$ \\
\hline LSIL/HSIL & $16(16 \%)$ & $3(3 \%)$ & $81(81 \%)$ \\
\hline Normal Inflammatory & $21(21 \%)$ & $60(60 \%)$ & $\mathbf{1 0 0}(100 \%)$ \\
\hline Total & $\mathbf{3 7}(\mathbf{3 7 \% )}$ & $\mathbf{6 3 ( 6 3 \% )}$ & \\
\hline
\end{tabular}

Sensitivity $=43.2 \%$

Specificity $=95.2 \%$

Positive predictive value $=84.1 \%$

Negative predictive value $=74.07 \%$

Accuracy $=76.0 \%$

$P$ value $\left[\mathrm{chi}^{2}\right]=\mathrm{p}<0.001[22.4]$
Positive Pap smear [LSIL/HSIL] was significantly associated with LSIL/HSIL/malignancy ( $\mathrm{p}<0.001, \mathrm{Chi}^{2}=$ 22.4).

Also, positive Pap smear [LSIL/HSIL] was significantly associated with malignancy $\left(\mathrm{p}=0.002, \mathrm{Chi}^{2}=13.1\right)$.

\begin{tabular}{|c|c|c|c|c|c|c|}
\hline \multirow[b]{2}{*}{ RCI } & \multicolumn{5}{|c|}{ BIOPSY } & \multirow[b]{2}{*}{ Total } \\
\hline & Normal & $\begin{array}{l}\text { Cervicitis/ } \\
\text { Metaplasia }\end{array}$ & LSIL & HSIL & Malignancy & \\
\hline $0-2$ & $3(3 \%)$ & $24(24 \%)$ & $1(1 \%)$ & $1(1 \%)$ & $0(0 \%)$ & $29(29 \%)$ \\
\hline $3-4$ & $0(0 \%)$ & $33(33 \%)$ & $12(12 \%)$ & $3(3 \%)$ & $0(0 \%)$ & $48(48 \%)$ \\
\hline $5-8$ & $0(0 \%)$ & $3(3 \%)$ & $6(6 \%)$ & $11(11 \%)$ & $3(3 \%)$ & $23(23 \%)$ \\
\hline Total & $3(3 \%)$ & $60(60 \%)$ & $19(19 \%)$ & 15 (15\%) & $3(3 \%)$ & $100(100 \%)$ \\
\hline
\end{tabular}

37 out of 100 women were positive on biopsy.

Out of 29 cases reported under RCI $0-2,1$ case proved to be CIN 1; 24 cases of cervicitis were over-reported as CIN 1 and 1 case of HSIL was under-reported as CIN 1.

15 cases under RCI 3 - 5 were reported as LSIL/HSIL and 33 cases of cervicitis were over-reported.

Out of 23 cases of RCI 6 - 8, 3 cases were under-reported which came out to be malignant on biopsy; 3 cases of cervicitis were over-reported and 17 cases as LSIL/HSIL.

Test applied Chi square test.

High RCI [6 - 8] was significantly associated with Malignancy $\left[\mathrm{P}=0.001, \mathrm{Chi}^{2}=10.5\right]$.

High RCI [6 - 8] was significantly associated with HSIL. $\left[\mathrm{P}<0.001, \mathrm{Chi}^{2}=31.4\right]$.

RCI [3 - 5] was not significantly associated with HSIL $\left[\mathrm{p}=0.56, \mathrm{Chi}^{2}=0.32\right]$.
Association of RCI [3 - 5] with Malignancy could not be established, as there is no positive case.

\begin{tabular}{|c|c|}
\hline RCI & Positive Predictive Value for Biopsy \\
\hline $0-2$ & 6.9 \\
\hline $3-4$ & 31.3 \\
\hline $5-8$ & 87.0 \\
\hline $\begin{array}{r}\text { Table 11. Relation between Reid Colposcopy Index and } \\
\text { Positive Predictive Value for Biopsy }\end{array}$ \\
\hline
\end{tabular}

RCI 5 - 8 is associated with high positive predictive value (87\%) for biops

\section{DISCUSSION}

The incidence of cervical cancer can be reduced by as much as $80 \%$ if the quality, coverage and follow-up of screening methods are of high standard.11 
In the present study, the maximum number of patients was in the age group of 31 - 40 years $(41 \%)$ and mean age was 37.85 years which was similar to study by Rawson et al 1957.12 Sedlis et al (1979) stated that the highest rate of dysplasia is found in 20 - 29 years' age group. ${ }^{13}$ In a study by Deshpande Sonali et al, mean age of the study group was 36.5 years with a range of 21 - 63 years. ${ }^{14}$ The mean age of squamous intraepithelial lesion is higher in our study than the mean age in other studies. This may be because the patients in our study usually came for other gynaecological problems at a later age and not specifically for screening.

\section{Parity}

Majority of the study group were para two (33\%) and para three (34\%).

All patients of severe dysplasia were multiparous. It is similar to the findings of Christopherson and Parker 1960.15

Maliphant (1949), stressed the increasing risk of malignancy with each pregnancy. He found that the risk of malignancy in married women with children was twice as compared to the married women without children and it was ten times more when unmarried women were taken into consideration. ${ }^{16}$

Purandare et al (1977) in their study found a stepwise chronological progression in severity of epithelial abnormalities increasing with abnormal smear in the years of married life. The number of epithelial abnormalities increased with the parity. ${ }^{17}$

Juneja et al in 1993, did a study concluding that the rate of malignancy was higher in women above 40 years and those with 2 children or more. ${ }^{18}$

Sujathan et al concluded that those subjects with a parity of more than 3 and a marital life of more than 20 years had a significantly higher number of cytological abnormalities. ${ }^{19}$

\section{Symptom}

In our study, the commonest symptom was recurrent white discharge per vagina (79\%) similar to study done by Deshpande Sonali et al ${ }^{14}$ (85\%).

Maximum number of cases were found to be in the upper lower (68\%) socioeconomic status as per Modified Kuppuswamy Scale.

In $93 \%$ cases, the age at first intercourse age $<20$ years.

Coital frequency was 5 - 14 per month in $67 \%$ cases, which is similar to study by Rotkin et al.

\section{Pap Smear}

In our study, sensitivity of Pap smear was found to be $43.2 \%$. This is because 15 cases of mild dysplasia (LSIL) and 6 cases of moderate-to-severe dysplasia (HSIL) were under-reported as inflammatory. Positive Pap smear [LSIL/HSIL] was significantly associated with LSIL/HSIL/malignancy ( $p$ < 0.001, Chi $^{2}$ [22.4]) Also, positive Pap smear [LSIL/HSIL] was significantly associated with malignancy $\left[\mathrm{p}=0.002, \mathrm{Chi}^{2}=\right.$ 13.1]. As a screening test, the Pap smear has been found to have a low sensitivity between $44 \%$ and $50 \%$, resulting in a high false negative rate of $36 \%-40 \% .^{20}$ The sensitivity of Pap smear has been found to be lower in developing countries, because of presence of infection and inflammation. The high specificity of Pap smear (95.2\%) found in our study is similar to findings from other studies in which specificity ranges from $91 \%-97 \% .^{20}$ In a prospective study by Goel A et al, the sensitivity of Pap smear was $50 \%$ and specificity was $92.4 \% .{ }^{21}$ In our study, the positive predictive value was found to be $84.2 \%$, negative predictive value was $74.07 \%$ and accuracy was $76 \%$.

\section{Colposcopy and Histology}

100 patients with abnormalities on colposcopy underwent directed biopsy. Biopsy was taken from the most abnormal area. Colposcopy result was classified according to the modified Reid Colposcopic Index. Out of the 23 cases that came in the high-grade category (RCI 5 - 8), histopathology report was malignancy in 3 cases, HSIL in 11 cases and LSIL in 6 cases; 3 cases were negative for dysplasia which were over-reported in colposcopy. Therefore, the correct histological prediction happened in 11 cases out of 23 giving an agreement of $47.82 \%$; 3 cases $(13.04 \%)$ were overreported, i.e. histology was less advanced than expected; 6 cases $(26.08 \%)$ were under-reported. Out of 48 cases of RCI $3-4$, LSIL/HSIL was confirmed by biopsy in 15 cases $(31.25 \%)$ and 33 cases were negative for dysplasias (68.75\%).

In 29 cases, which were colposcopically reported as RCI $0-2,1$ case was histologically confirmed as LSIL/CIN1 (3.44\%), 1 case as HSIL (3.44\%) and 27 cases were negative for dysplasia (93.10\%). Correlation between colposcopic findings and biopsy showed a good correlation for higher grade lesions (CIN III). In our study, the positive predictive value of RCI 5 - 8 group is $87 \%$. High RCI [6 - 8] was significantly associated with malignancy. $\left[\mathrm{P}=0.001, \mathrm{Chi}^{2}=\right.$ 10.5]. High RCI [5 - 8] was significantly associated with HSIL $\left[\mathrm{P}<0.001, \mathrm{Chi}^{2}=31.4\right]$. RCI [3 - 4] was not significantly associated with HSIL $\left[\mathrm{p}=0.56, \mathrm{Chi}^{2}=0.32\right]$ association of RCI [3 - 4] with malignancy could not be established, as there is no positive case.

In a study by Ancuţa Boicea et al, 245 patients presented with malignant findings at colposcopy and biopsy. Colposcopic findings: 28 (11.4\%) cases were CIN I, 50 (20.4\%) cases were CIN II, 150 (61.2\%) cases were CIN III, 13 $(5.3 \%)$ cases were microinvasive carcinoma and four $(1.6 \%)$ cases were CIS. Histological results in the 245 examined cases were $4(1.6 \%)$ cases normal, $26(10.6 \%)$ cases CIN I, 55 (22.4\%) cases CIN II, 138 (56.3\%) cases CIN III, 15 (6.1\%) cases microinvasive carcinoma and seven $(2.8 \%)$ cases of CIS. The correlation was $78.5 \%$ in the CIN I category, $84 \%$ in the CIN II category, $88.6 \%$ (133 out of 150 patients) in the CIN III category, $46.1 \%$ for microinvasive carcinoma and $50 \%$ for CIS. The colposcopy method incurred fewer false negatives (four patients), giving a general accuracy rate of $98.3 \%$. Sensitivity of colposcopic examination was $83.6 \% .^{22}$

Massad et al in 2002 performed colposcopies on 2825 women. Exact agreement was on 893 women (37\%), but results agreed within 1 grade in $75 \%$ cases. ${ }^{23}$ Boonlikit $S$ in 2011, studied the correlation between Reid's Colposcopic Index and histologic results from biopsy in 100 patients. Overall, predictive accuracy was $89 \%$ and had good correlation with histology.24 Stafl and Mattingly found correlation between colposcopy and histology to be $85 \%$. Histology was less advanced than expected in $11.7 \%$ cases and more advanced than expected in $3.3 \%$ cases. ${ }^{25}$ 
Javaheri et al did colposcopy and directed biopsy on patients with abnormal Pap smears. They achieved a histological correlation of $85.9 \%$ in high-grade lesions and a correlation of $95.9 \%$ in low-grade lesions; $12.2 \%$ patients had less advanced histological diagnosis in the high-grade lesion group. ${ }^{26}$

Maziah AM et al in 1991, in a comparative study of cytologic and colposcopic findings in preclinical cervical cancer, obtained an accuracy rate of $94 \%$ for colposcopy. The colposcopic findings rates were: $10 \%$ for CIN I, $34 \%$ for CIN II, $34 \%$ for CIN III and $12 \%$ for invasive carcinoma. Histology findings were: $10 \%$ were CIN I, $20 \%$ were CIN II, $60 \%$ were CIN III and $10 \%$ were micro-invasive carcinoma. ${ }^{27}$

Díaz-Amézquita EL et al in 2006, in a study of establishing cytologic, histologic and colposcopic correlations of low- and high-grade cervical lesions found a $69.61 \%$ rate (142 of 204).28 Olaniyan OB et al in 2002, conducted a meta-analysis to quantify the validity of colposcopy in the diagnosis of early cervical neoplasia. Eight longitudinal studies were selected, which compared correlation of colposcopic impression with colposcopically directed biopsy results. The prevalence of cervical disease in the studies ranged from $40 \%$ to $89 \%$. Colposcopic accuracy was $89 \%$, which agreed exactly with histology in $61 \%$ of cases. The sensitivity and specificity of colposcopy for the threshold of normal vs. all cervical abnormalities were $87 \%-99 \%$ and $26 \%$ - $87 \%$ respectively. For the threshold of normal and low-grade SIL vs. high-grade SIL, the values were $30 \%-90 \%$ and $67 \%-97 \% .^{29}$

Brotzman GL et al in 2004, in a study made on 564 patients observed that the colposcopic impression correctly predicted the presence of LSIL compared with gold standard biopsy results in $64.3 \%$ of the time. The colposcopic impression of HSIL, compared with biopsy results correctly predicted the presence of HSIL $70 \%$ of the time. There was a $12.7 \%$ error rate in discriminating normal from LSIL. ${ }^{30}$

Moss EL et al, in 2009 studied 469 patients to determine whether colposcopy is reliable in diagnosing cervical intraepithelial neoplasia in women who have undergone a previous cervical excision biopsy: the sensitivity and specificity of colposcopy for any cervical disease were $93.9 \%$ respectively $51.9 \% .31$ Pimple SA et al in 2010 made an evaluation of colposcopy vs. cytology as secondary test to triage women found positive on visual inspection test. The colposcopic impression was CIN I in $33.8 \%$ of cases, CIN II-III in $8.6 \%$ of cases, and invasive carcinoma in $2.7 \%$ of cases. Histopathology findings were reported as benign in $81.6 \%$, CIN I in $5.8 \%$ of cases, CIN II in $2.9 \%$ of cases, CIN III in $2.6 \%$ of cases and invasive carcinoma in $2.9 \%$ of cases. The estimates of sensitivity for low- and high-threshold colposcopy were $58 \%$ and $74.5 \%$ respectively, and those of specificity were $57.5 \%$ and $92.9 \%$ respectively. ${ }^{32}$

\section{CONCLUSION}

Cervical cancer develops from well-defined precursor lesions in a varied period of time. Detected in early or pre-invasive stages cervical cancer is preventable and curable, so detection of precancerous lesions is very important.

In our study, we found high correlation between colposcopy and histology in the RCI 6 - 8 group.
Also, there is high positive predictive value of RCI 6 - 8 group. Colposcopy with directed biopsy is used in the evaluation and management of patients with cervical lesions and described as the 'gold standard' for the diagnosis of cervical precancer.

Pap smear had a poorer sensitivity, but a better specificity. Hence, it may be better to utilise both tests as they complement each other in screening of precancerous lesions. While the Pap smear discovers the crime, colposcopy locates the culprit.

\section{REFERENCES}

[1] Arora R, Vijaya K, Habeebullah S, et al. Colposcopic evaluation of unhealthy cervix. J Obstet Gynecol Ind 2000;50:102-3.

[2] Kaarthigeyan K. Cervical cancer in India and HPV vaccination. Indian $\mathrm{J}$ Med Paediatr Oncol 2012;33(1):7-12.

[3] ACOG committee on practice bulletins--gynecology. ACOG practice bulletin no. 109: cervical cytology screening. Obstet Gynecol 2009;114(6):1409-20.

[4] American Cancer Society. Cancer Facts \& Figures 2012. Atlanta GA, 2012.

[5] Horner MJ, Ries LAG, Krapcho M, et al. SEER cancer statistics review, 1975-2006. National Cancer Institute. 2009.

[6] U.S. Cancer Statistics Working Group. United States cancer statistics: 1999-2007 incidence and mortality webbased report. Department of Health and Human Services, Centers for Disease Control and Prevention, and National Cancer Institute. 2010.

[7] Berek JS. Berek and Novak's Gynecology. 13 $3^{\text {th }}$ edn. Lippincott Williams and Wilkins, Philadelphia, 2002:pp 1199.

[8] Konar H. DC Dutta's Textbook of Gynaecology. $5^{\text {th }}$ edn. New Central Book Agency Ltd., Kolkata, 2008:pp 334.

[9] Das SK, Nigam S, Batra A, et al. An atlas of colposcopy, cytology and histopathology of lower female genital tract. New Delhi, CBS Publishers and Distributors, 2008:pp 129.

[10] Das SK, Nigam S, Batra A, et al. An atlas of colposcopy, cytology and histopathology of lower female genital tract. New Delhi, CBS Publishers and Distributors, 2008:2-3.

[11] Sankanarayanan R, Madhukar AB, Rajkumar R. Effective screening programs for cervical cancer in low and middle income developing countries. Bull World Health Organ 2001;79(10):954-62.

[12] Knoblich R, Rawson AJ. A clinicopathological study of 56 cases showing atypical epithelial changes of the cervix uteri. Am J Obstet Gynecol 1957;73(1):120-6.

[13] Sedlis A, Sall S, Tsukada Y, et al. Microinvasive carcinoma of the uterine cervix: a clinical-pathologic study. Am J Obstet Gynaecol 1979;133(1):64-74.

[14] Sonali D, Kanan Y, Smita A, et al. Role of colposcopy using modified reid's index in screening of cervical cancer in women with abnormal cervix on naked eye examination. Journal of Evolution of Medical and Dental Sciences 2014;3(4):902-6. 
[15] Christopherson WM, Parker JE. A study of the relative frequency of carcinoma of the cervix in the Negro. Cancer 1960;13:711-3.

[16] Maliphant RG. The incidence of cancer of the uterine cervix. Br Med J 1949;1(4613):978-82.

[17] Chitale AR, Bhuvaneshwari AP, Khilnani P, et al Pathology of microinvasive (Stage 1 a) carcinoma of uterine cervix. Indian J Cancer 1977;14(3):189-94.

[18] Juneja A, Murthy NS, Sharma S, et al. Selective cervical cytology screening: discriminant analysis approach. Neoplasma 1993;40(6):401-4.

[19] Sujathan K, Kannan S, Pillai KR, et al. Implications of gunaecological abnormalities in pre-selection criteria for cervical screening: preliminary evaluation of 3602 subjects in south India. Cytopathology 1995;6(2):7587.

[20] University of Zimbabwe/JHPIEGO Cervical Cancer Project. Visual inspection with acetic acid for cervical cancer screening: test qualities in a primary-care setting. Lancet 1999;353(9156):869-73.

[21] Goel A, Gandhi G, Batra S, et al. Visual inspection of the cervix with acetic acid for cervical intraepithelial lesions. Int J Gynecol Obstet 2005;88(1):25-30.

[22] Boicea A, Pătraşcu A, Şurlin V, et al. Correlations between colposcopy and histologic results from colposcopically directed biopsy in cervical precancerous lesions. Rom J Morphol Embryol 2012;53(3 Suppl):735-41.

[23] Massad LS, Collins YC. Strength of correlations between colposcopic impression and biopsy histology. Gynaecol Oncol 2003;89(3):424-8.
[24] Boonlikit S. Correlation between Reid's colposcopic index and histological results from colposcopically directed biopsy in differentiating high grade from low grade squamous intraepithelial lesions at Rajavithi hospital. J Med Assoc Thai 2011;94(Suppl 2):S59-65.

[25] Stafl A, Mattingly RF. Colposcopic diagnosis of cervical neoplasia. Obstet Gynecol 1973;41(2):168-76.

[26] Javaheri G, Fejgin MD. Diagnostic value of colposcopy in the investigation of cervical neoplasia. Am J Obstet Gynecol 1980;137(5):588-94.

[27] Maziah AM, Sharifah NA, Yahya A. Comparative study of cytologic and colposcopic findings in preclinical cervical cancer. Malays J Pathol 1991;13(2):105-8.

[28] Díaz-Amézquita EL, Martínez LN, Dragustinovis VIY. Correlación citológica-colposcópica e histological de lesiones de bajo y alto grado en cervix. Rev Hosp Gral Dr. M Gea González 2006;7(2):54-8.

[29] Olaniyan OB. Validity of colposcopy in the diagnosis of early cervical neoplasia-a review. Afr J Reprod Health 2002;6(3):59-69.

[30] Brotzman GL, Schellhase KG. Colposcopic proficiency disease spectrum in a single family practice colposcopists' clinic. WMJ 2004;103(7):61-5.

[31] Moss EL, Dhar KK, Byrom J, et al. The diagnostic accuracy of colposcopy in previously treated cervical intraepithelial neoplasia. J Low Genit Tract Dis 2009;13(1):5-9.

[32] Pimple SA, Amin G, Goswami S, et al. Evaluation of colposcopy vs cytology as secondary test to triage women found positive on visual inspection test. Indian J Cancer 2010;47(3):308-13. 